\title{
Monitoramento da Qualidade do Ar Interior de uma Escola da Rede Pública Localizada no Município de Cuiabá-MT
}

\section{Quality Monitoring Indoor Air of a School of Public Network Located in the city of Cuiaba-MT}

\author{
${ }^{1}$ Danila Soares Caixeta, ${ }^{2}$ Thayná Albuquerque Silva, ${ }^{3}$ Felipe Matheus Ferdinando Santana, ${ }^{5}$ Winícios \\ Thiago Pereira Almeida \\ ${ }^{1}$ Doutora em Microbiologia Agrícola - UFLA, Profa Pesquisadora no Programa de Mestrado em Recursos Hídricos-PPGRH \\ /Universidade Federal de Mato Grosso UFMT, Profa no Departamento de Engenharia Sanitária e Ambiental-DESA/UFMT \\ 2,3,4,5 Graduandos do DESA-UFMT \\ Recebido em: Novembro de 2015 Aceito em: Janeiro de 2016 Publicado em:Junho de 2016
}

RESUMO: Edifícios aclimatados artificialmente por serem hermeticamente fechados, causam a redução da captação do ar externo, apresentando problemas quanto à regulagem da umidade e temperatura do ar e, consequentemente, o aparecimento de diferentes espécies de micro-organismos. Este estudo objetivou monitorar mensalmente a qualidade do ar de uma escola da rede pública do município

de Cuiabá. Dos onze pontos amostrados, nove apresentaram concentração de bactérias superior à permitida pela Legislação em vigência, em pelo menos um dos meses de análise. Considerando o estabelecido na Legislação, nenhum ponto obteve valores superiores a $750 \mathrm{UFC} / \mathrm{m}^{3}$. Salienta-se que a contaminação biológica, aliada à temperatura e umidade dos ambientes escolares, além de causarem desconforto físico e psicológico, desempenham um papel importante na causalidade dos agravos à saúde.

PALAVRAS- CHAVE: Microrganismos, Ambiente escolar, Saúde pública.

ABSTRACT: Artificially air-conditioned buildings are sealed, cause a reduction of the uptake of the external air, presenting problems regarding the regulation of the humidity and air temperature and hence the appearance of different species of micro-organisms. This study aimed to monthly monitor the air quality of a public school in the city of Cuiaba. Of the eleven sampled points, nine had higher concentration of bacteria that permitted by legislation in force, at least one of the months of analysis. Considering the provisions of Legislation, no points obtained values greater than $750 \mathrm{CFU} / \mathrm{m}^{3}$. Please note that biological contamination, together with the temperature and humidity of school environments, and cause physical and psychological discomfort, play an important role in the causation of health problems.

KEYWORDS: Microorganisms, School environment, Public health.

\section{INTRODUÇÃO}

$\mathrm{O}$ ar é um dos compartimentos do ecossistema que mais tem sofrido com os poluentes provenientes das atividades antrópicas, principalmente nas aglomerações urbanas. No entanto, nas últimas décadas, a qualidade do ar de ambientes internos tem sido enfoque de várias discussões e pesquisas, por refletir diretamente na qualidade de vida e saúde da população.

A Organização Mundial de Saúde (OMS) (1999) estima que cerca da metade da população sofra com a má Qualidade do Ar Interior (QAI), principalmente em países subdesenvolvidos ou em desenvolvimento, com comprometimento dos sistemas respiratório e cardiovascular, além de doenças nos olhos, nariz, garganta, pele, cabeça e pulmões.

No entanto, os edifícios aclimatados artificialmente podem criar um ambiente ameaçador à saúde humana. Por serem hermeticamente fechados, causam a redução da captação do ar externo, apresentando problemas quanto à regulagem da umidade e temperatura do ar $\mathrm{e}$, consequentemente, o aparecimento de diferentes espécies de micro-organismos. De fato, a falta de uma política preventiva nos programas de manutenção nos sistemas de refrigeração e ventilação pode ser fator determinante para a ocorrência de poluentes biológicos, que na maioria das vezes são micro-organismos patogênicos, os quais poderão constituir uma ameaça à 
saúde dos seus ocupantes (Quadros e Lisboa, 2010).

Os bioaerossóis, que constituem a microbiota dispersa no ar (fungos, bactérias, algas, vírus, entre outros), quando presentes no ar interno, podem causar irritações, alergias, doenças e outros efeitos tóxicos. O agente microbiano é inalado por via aérea e fica retido no trato respiratório, ou em local propício ao seu desenvolvimento.

No Brasil, a qualidade do ar em ambientes internos começou a ser regulamentada a partir da publicação da Portaria $n^{\circ} 3523$, de 28 de agosto de 1998, da Agência Nacional de Vigilância Sanitária (ANVISA). Esta aprovou o regulamento técnico para manutenção e limpeza de sistemas de climatização de ambientes. Anos depois, foi publicada a Resolução no 9, em 16 de janeiro de 2003, da ANVISA que atualizou os padrões referenciais de qualidade do ar interior em ambientes climatizados artificialmente de uso público.

A Qualidade do Ar Interior nas escolas é um tema relativamente recente na literatura e a maioria dos estudos, a nível mundial, foram realizados na Europa, América do Norte e em alguns pontos da Ásia, enquanto os estudos brasileiros pioneiros foram realizados na região sudeste (Comin, 2012). Ferreira e Cardoso (2013), avaliaram a qualidade do ar de 51 escolas de educação básica de Coimbra/Portugal, sendo que os resultados mostraram que houve elevada concentração de poluentes no interior das salas.

A importância de monitorar a Qualidade do Ar Interior em salas de aula decorre do fato de que além das crianças e jovens passarem, em média, $25 \%$ do tempo (6 horas diárias) nas escolas, eles constituem uma faixa etária de risco. Aliado a isso, existe o fato de que muitas escolas carecem de um eficiente programa de manutenção predial e apresentam deficientes taxas de ventilação, que somadas às altas taxas de ocupação das salas de aula, contribuem para a má qualidade do ar interior, comprometendo, além da saúde, o desempenho dos estudantes.

Diante da problemática, dos ambientes escolares climatizados artificialmente, este estudo objetivou monitorar mensalmente a qualidade do ar de uma escola da rede pública do município de Cuiabá, utilizando-se como parâmetro a Resolução ${ }^{\circ}$ 09, da Agência Nacional de Vigilância Sanitária, de 16 de janeiro de 2003, Brasil e o Decreto-Lei n. ${ }^{\circ}$ 79, de 4 de abril de 2006, Portugal.

\section{MATERIAIS E MÉTODOS}

\section{Área de estudo}

O presente estudo foi desenvolvido em uma escola pública, localizada em um bairro periférico da cidade de Cuiabá-MT.

As análises foram realizadas de abril a dezembro de 2013, no período diurno, enquanto ocupado pelos usuários. Para análise foram selecionados 11 pontos de amostragem, distribuídos uniformemente dentro da escola, caracterizados por apresentarem diferentes tipos de climatização, conforme descrito abaixo.

- Ponto 1: biblioteca - refrigerada por ar condicionado

- Ponto 2: secretaria - refrigerada por ar condicionado

- Ponto 3: sala dos professores refrigerada por ar condicionado

- Ponto 4: sala de informática refrigerada por ar condicionado

- Ponto 5: refeitório - natural

- Ponto 6: sala 1 - refrigerada por ventiladores;

- Ponto 7: ambiente externo;

- Ponto 8: sala 2 -refrigerada por dois ares condicionados;

- Ponto 9: sala 3, refrigerada por ventiladores;

- Ponto 10: sala 4, refrigerada por ventiladores;

- Ponto 11: sala 5, refrigerada por ventiladores. 
Aferição de temperatura e umidade relativa do ar

Para coleta dos dados referentes à temperatura e umidade foi utilizado um termo-higrômetro digital, da marca Hobo. Para a medição da temperatura e da umidade dos locais amostrados, o aparelho foi colocado sobre uma superfície à 1,5 metros do chão.

\section{Isolamento de microrganismos}

A técnica utilizada foi a de amostragem global de bioaerossóis (viáveis e não viáveis), feita através da impactação sobre meio de cultura sólido, caracterizando uma amostragem ativa.

Foram utilizados dois aparelhos de amostragem microbiológica portátil de ar SAS SUPER ISO 100/180, com uma taxa de vazão de 33,4 1/min. Para a coleta dos dados, em cada ponto de amostragem, os dois aparelhos foram colocados a uma altura de 1,5 metros do piso, obedecendo à Norma Técnica 001 da RE/ANVISA n ${ }^{\circ} 9$ de 2003.

Para o isolamento das bactérias foram utilizadas placas de Petri contendo o meio de cultura Ágar Nutriente, e para o isolamento de fungos, o meio de cultivo utilizado foi o Ágar Sabouraud Dextrose.

As placas de Petri utilizadas para o crescimento de bactérias, foram incubadas a $37^{\circ} \mathrm{C}$ por $24-48$ horas, enquanto que as placas de Petri empregadas para 0 crescimento de fungos, foram acondicionadas a $25^{\circ} \mathrm{C}$ por um período de 7 dias. Após o período de incubação foi realizada contagem padrão em placas e os valores expressos em Unidades Formadoras de Colônias por metro cúbico $\left(\mathrm{UFC} / \mathrm{m}^{3}\right)$.

\section{RESULTADOS E DISCUSSÃO}

Os resultados obtidos nesse estudo mostram as condições climáticas e microbiológicas dos ambientes internos e externos de uma escola da rede pública localizada na periferia da cidade de Cuiabá/MT.

Segundo Madureira et al. (2015), a Qualidade do Ar Interior é determinada por uma combinação de inúmeras poluentes originado a partir de um amplo espectro de fontes de poluição, estando associadas ao local, o clima, cultura, características do edifício e atividade interna.

\section{Temperatura e Umidade}

De acordo com a Resolução $\mathrm{n}^{\circ}$ 9, de 16 de janeiro de 2003, da ANVISA, podem-se observar valores de temperatura e umidade acima do recomendável, onde a faixa máxima de operação das Temperaturas nas condições internas para verão deverá variar de $26,5^{\circ} \mathrm{C}$ a $27^{\circ} \mathrm{C}$, com exceção das áreas de acesso que poderão operar até $28^{\circ} \mathrm{C}$, enquanto que para condições internas para inverno, a faixa recomendável de operação deverá variar de $20^{\circ} \mathrm{C}$ a $22^{\circ} \mathrm{C}$.

No gráfico 1 são mostrados os valores de aferição de temperatura durante o monitoramento no período de abril a dezembro de 2013.

Gráfico 1 Temperatura dos pontos de amostragem.

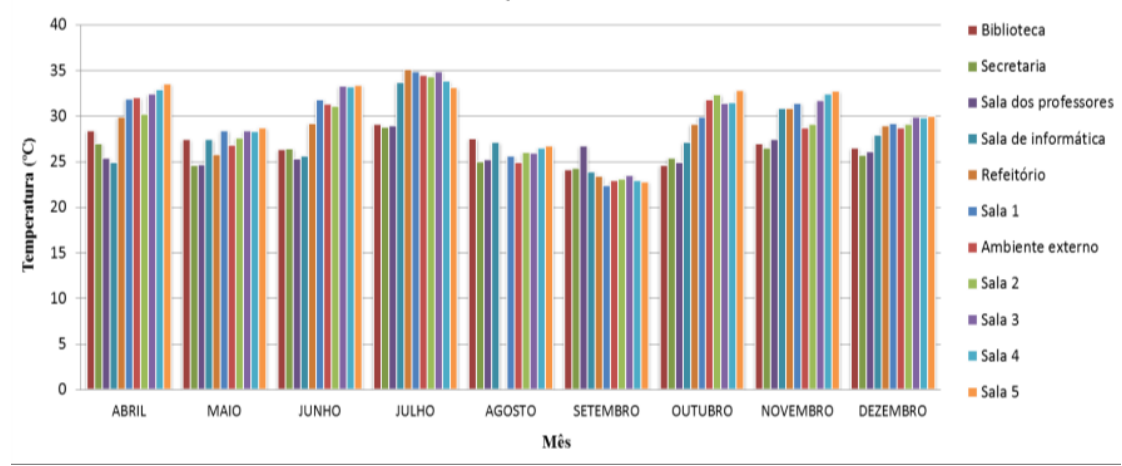

Fonte: Elaborado pelos autores 
Nos resultados mostrados no Gráfico 1 , verifica-se que a maioria dos pontos que caracterizam área interna apresentaram temperaturas próximas ao ambiente externo. Uma vez que essa variação de temperatura é pequena, há indícios de desconforto térmico, pois a variação no interior é aproximadamente igual ao exterior, quando isso não deveria acontecer, (Nascimento, 2011). Tal fato pode estar relacionado, principalmente, a ausência de mecanismos de refrigeração artificial.

O mês de setembro foi o que apresentou menor faixa de temperatura, sendo a menor temperatura na sala 1 , com valor de $22,5^{\circ} \mathrm{C}$.

Em contrapartida, no mês de julho, ocorreu a maior temperatura, com destaque para o refeitório, sala 1 e sala 3 . Já as salas de aula, inclusive a que é refrigerada com ar condicionado, ultrapassaram os limites estabelecidos pela legislação em todos os meses de amostragem, conforme mostra o Gráfico 1. Segundo Pereira et al. (2012), todas as edificações geram carga térmica por meio de máquinas, equipamentos, iluminação, circulação de pessoas e atividades exercidas no local. Aliado a isso, o tipo da construção, o clima do local e orientação geográfica do prédio influem decisivamente na dissipação ou na retenção dessa carga térmica.

Os resultados mostram uma situação preocupante, já que não só os alunos, como

\section{Gráfico 2 Umidade relativa dos pontos de amostragem.}

os professores e outros membros da equipe da escola, necessitam de boas condições de temperatura para que possam ter máximo rendimento nas suas atividades. Estudos recentes comprovam que o desconforto proporcionado por ambientes quentes ou frios reduzem o desempenho dos alunos, comprometendo o processo de ensinoaprendizagem e a saúde física e psicológica tanto dos alunos quanto dos professores. De acordo com Silva (2008), em situações de muito calor, o organismo precisa dissipar energia para obter o equilíbrio térmico, provocando uma tensão térmica que, devido aos mecanismos de termorregulação, ocasiona diversas reações fisiológicas como, sudorese, aumento da pulsação, aumento da temperatura interna, desequilíbrio no balanço hídrico e salino do organismo e sobrecarga do coração e aparelho circulatório.

Pereira et. al. (2009), mencionam que o trabalho sob condições de calor implica na redução do desempenho físico e mental dos docentes, e quando esse estresse térmico é prolongado, ocorre a perda de fluidos corporais, deteriorando as funções mentais e psicomotoras.

Outro parâmetro analisado, que influencia diretamente na qualidade microbiológica do ambiente, é a umidade relativa do ar. Os resultados estão expostos no Gráfico 2

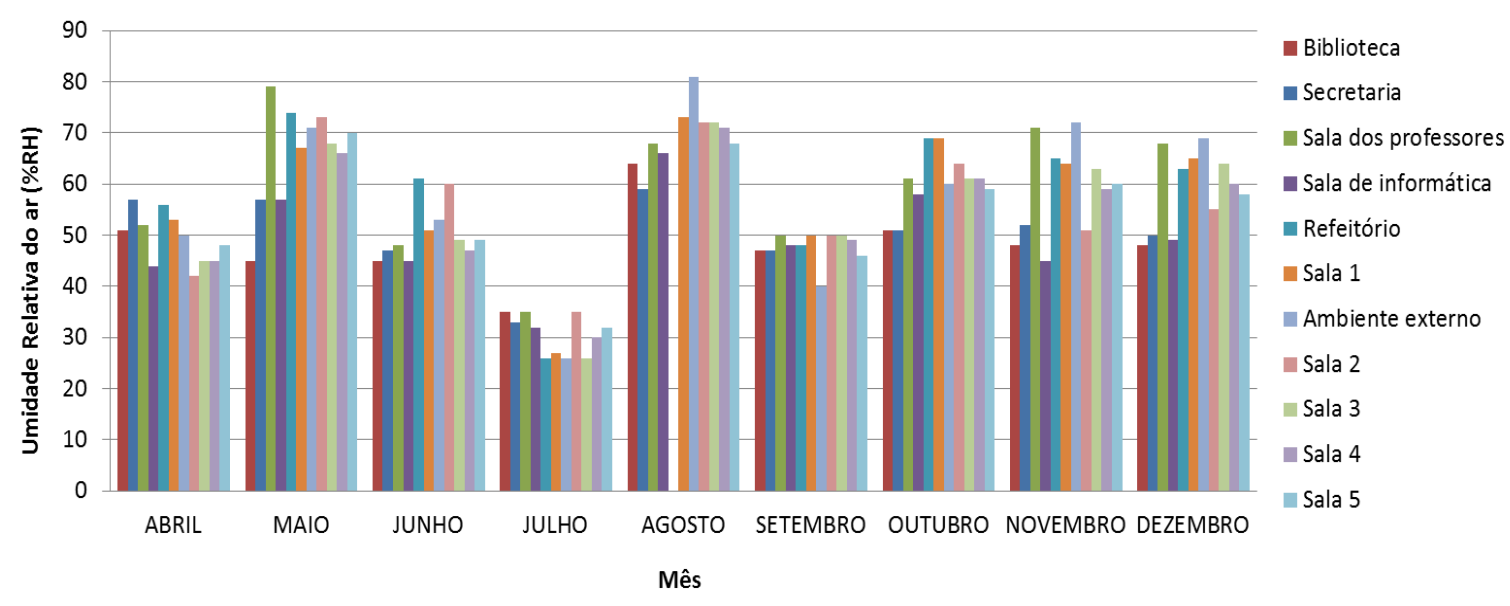

Fonte: Elaborado pelos autores 
Nos meses de abril, junho e setembro, todos os pontos amostrados apresentaram umidade relativa entre $40 \%$ e $65 \%$, obedecendo a legislação vigente, que estabelece uma faixa recomendável de operação, nas condições internas para verão, de $40 \%$ a $65 \%$, com exceção das áreas de acesso que poderão operar até $70 \%$, e condições internas para inverno, uma faixa recomendável de operação $35 \%$ a $65 \%$.

A maior discrepância de resultados, em relação às faixas recomendadas pela legislação, foi identificada nos meses de julho (faixas de umidade inferior à $40 \%$ ), maio e agosto (faixas de umidade superior à 65\%). No mês de julho, em todos os pontos a umidade relativa do ar esteve abaixo do estabelecido na legislação, sendo que em alguns pontos esses valores estiveram abaixo de $30 \%$, caracterizando um estado de atenção.

A alta umidade relativa do ar é um dos fatores que mais influenciam o crescimento e a liberação de contaminantes biológicos no ar, uma vez que ela permite o aumento das populações de ácaros e o crescimento de fungos sobre superfícies úmidas (Batista, 2008). Segundo Davis et al. (2016), a umidade e temperatura afeta alguns mecanismos do organismo humano, principalmente relacionadas ao estresse térmico e o estado de hidratação, o que consequentemente pode exercer pressão sobre o sistema cardiovascular, provocar doença renal, doenças pulmonares, doenças do trato intestinal e até morte prematura.

\section{Contaminação bacteriana e fúngica}

Madureira et al. (2015), mencionam que Qualidade do Ar Interior nas escolas é genericamente caracterizado por uma complexidade dos vários poluentes, tais como compostos orgânicos voláteis, material particulado, aldeídos, bactérias e fungos.

No Brasil, a Resolução RE/ANVISA $\mathrm{n}^{\circ}$ 9, de 16 de janeiro de 2003, estabelece Padrões Referenciais de Qualidade do Ar Interior em Ambientes Climatizados artificialmente de Uso Público e Coletivo, sendo que o Valor Máximo Recomendável - VMR, para contaminação microbiológica de fungo de $750 \mathrm{UFC} / \mathrm{m}^{3}$, e para a relação $\mathrm{I} / \mathrm{E} \leq 1,5$, onde I é a quantidade de fungos no ambiente interior e E é a quantidade de fungos no ambiente exterior. Salienta-se que essa resolução não estabelece valor máximo recomendável para a contaminação microbiológica de bactérias. Por outro lado, o Decreto-Lei n. ${ }^{\circ} 79$, de 4 de abril de 2006, de Portugal, estabelece o valor máximo de $500 \mathrm{UFC} / \mathrm{m}^{3}$.

Considerando o valor máximo de $500 \mathrm{UFC} / \mathrm{m}^{3}$, verifica-se na tabela 1 , alguns valores acima do desejável.

Tabela 1 Incidência de bactérias nos pontos de amostragem.

\begin{tabular}{c|c|c|c|c|c|c|c|c|c|c|c}
\hline Mês & $\begin{array}{c}\mathrm{P} 1 \\
(\mathrm{UFC} / \mathrm{m} 3)\end{array}$ & $\begin{array}{c}\mathrm{P} 2 \\
(\mathrm{UFC} / \mathrm{m} 3)\end{array}$ & $\begin{array}{c}\mathrm{P} 3 \\
(\mathrm{UFC} / \mathrm{m} 3)\end{array}$ & $\begin{array}{c}\mathrm{P} 4 \\
(\mathrm{UFC} / \mathrm{m} 3)\end{array}$ & $\begin{array}{c}\mathrm{P} 5 \\
(\mathrm{UFC} / \mathrm{m} 3)\end{array}$ & $\begin{array}{c}\mathrm{P} 6 \\
(\mathrm{UFC} / \mathrm{m} 3)\end{array}$ & $\begin{array}{c}\mathrm{P} 7 \\
(\mathrm{UFC} / \mathrm{m} 3)\end{array}$ & $\begin{array}{c}\mathrm{P} 8 \\
(\mathrm{UFC} / \mathrm{m} 3)\end{array}$ & $\begin{array}{c}\mathrm{P} 9 \\
(\mathrm{UFC} / \mathrm{m} 3)\end{array}$ & $\begin{array}{c}\mathrm{P} 10 \\
(\mathrm{UFC} / \mathrm{m3})\end{array}$ & $\begin{array}{c}\mathrm{P} 11 \\
(\mathrm{UFC} / \mathrm{m} 3)\end{array}$ \\
\hline ABRIL & 36 & 198 & 92 & 34 & 48 & 26 & 80 & 98 & 20 & 46 & 146 \\
MAIO & 18 & 4107 & 128 & 586 & 184 & 96 & 192 & 1084 & 192 & 108 & 116 \\
JUNHO & 36 & 176 & 234 & 248 & 894 & 224 & $>2614$ & $>2614$ & 1966 & 492 & $>2614$ \\
JULHO & 40 & 2 & 64 & 10 & 58 & 118 & 68 & 146 & 262 & 98 & 166 \\
AGOSTO & 14 & 20 & 50 & 10 & $*$ & 4 & 0 & 3 & 102 & 4 & 1 \\
SETEMBRO & 46 & 66 & 62 & 44 & 56 & 36 & 66 & 42 & 44 & 88 & 46 \\
OUTUBRO & 96 & 148 & 140 & $>2614$ & 22 & 572 & 114 & 564 & 36 & 234 & 364 \\
NOVEMBRO & 36 & 124 & 610 & 155 & 134 & 50 & 1478 & 202 & 324 & 156 & 22 \\
DEZEMBRO & 41 & 104 & 132 & 118 & 158 & 140 & 245 & 167 & 238 & 153 & 107 \\
\hline
\end{tabular}

*No mês de agosto não foi realizada a coleta de dados no ponto 5 por motivo de reforma. 
É possível observar, que dos onze pontos amostrados, nove apresentaram concentração de bactérias superior à permitida pela referida legislação, em pelo menos um dos meses de análise. As exceções se deram nos P1 (biblioteca) e P10 (sala 4).

Nota-se que no P2 (secretaria da escola) foi o local que apresentou, no mês de maio, a maior concentração de bactérias, sendo esta de $4107 \mathrm{UFC} / \mathrm{m}^{3}$. O P8 (sala 2) foi o ambiente que apresentou maior quantidade de meses com limite superior ao estabelecido, sendo os meses de maio, junho e outubro, com valores de 1084 , >2614 e 564, respectivamente.

Dentre o período de análise, destacase o mês de agosto, com o menor índice de contaminação bacteriana, na maioria dos pontos amostrados, com valor mínimo de 0 $\mathrm{UFC} / \mathrm{m}^{3}$ no ponto P7 (ambiente externo). Em contra partida, dos onze pontos amostrados, cinco (P5, P8, P9, P10 e P11) apresentaram os maiores valores no mês de junho. Os mesmos pontos, no referido mês, apresentaram altas taxas de temperatura e baixos valores de umidade, fatores que interferem diretamente sobre a incidência de bactérias.

Outro fator que pode estar relacionado ao alto índice de bactérias é a falta de manutenção periódica dos filtros do ar condicionado, falta de circulação de ar e a grande incidência de pessoas circulando nesses locais, uma vez que as cargas bacterianas podem ser carreadas pela sola de sapatos, boca, mãos e pele.

Existem inúmeras bactérias patogênicas que são veiculadas por meio de sistemas centrais de condicionamento de ar e de circulação de pessoas no ambiente, tais como Pseudomonas sp. que frequentemente está associada a infecções respiratórias e do trado urinário, podendo também, causar infecções sistêmicas; Legionella pneumophila que pode causar uma pneumonia conhecida como "doença dos legionários", sendo alguns dos sintomas febre, dores de cabeça e fraqueza; Mycoplasma responsável por uma forma branda de pneumonia; e Actinomyces que geralmente encontradas na boca e na garganta, podendo causar uma doença que afeta geralmente cabeça, pescoço e pulmões (Quadros e Lisboa, 2010).

Em relação aos fungos, os valores estão expressos na tabela 2.

Considerando o estabelecido na Resolução - RE/ANVISA n ${ }^{\circ}$, de 16 de janeiro de 2003, nenhum ponto obteve valores superiores a $750 \mathrm{UFC} / \mathrm{m}^{3}$. O maior índice foi no P9 $\left(536 \mathrm{UFC} / \mathrm{m}^{3}\right)$, no mês de agosto.

O mês de agosto foi o que apresentou maior frequência de contaminação fúngica, e o mês de julho o menor índice, sendo no $\mathrm{P} 6$ valor de $0 \mathrm{UFC} / \mathrm{m}^{3}$.

Tabela 2 Incidência de fungos nos pontos amostrados.

\begin{tabular}{c|c|c|c|c|c|c|c|c|c|c|c}
\hline Meses & $\begin{array}{c}\text { P1 } \\
\text { (UFC/m3) }\end{array}$ & $\begin{array}{c}\text { P2 } \\
\text { (UFC/m3) }\end{array}$ & $\begin{array}{c}\text { P3 } \\
\text { (UFC/m3) }\end{array}$ & $\begin{array}{c}\text { P4 } \\
\text { (UFC/m3) }\end{array}$ & $\begin{array}{c}\text { P5 } \\
\text { (UFC/m3) }\end{array}$ & $\begin{array}{c}\text { P6 } \\
\text { (UFC/m3) }\end{array}$ & $\begin{array}{c}\text { P7 } \\
\text { (UFC/m3) }\end{array}$ & $\begin{array}{c}\text { P8 } \\
\text { (UFC/m3) }\end{array}$ & $\begin{array}{c}\text { P9 } \\
\text { (UFC/m3) }\end{array}$ & $\begin{array}{c}\text { P10 } \\
\text { (UFC/m3) }\end{array}$ & $\begin{array}{c}\text { P11 } \\
\text { (UFC/m3) }\end{array}$ \\
\hline ABRIL & 74 & 40 & 84 & 48 & 214 & 120 & 516 & 90 & 292 & 108 & 402 \\
MAIO & 9 & 92 & 74 & 48 & 412 & 238 & 504 & 374 & 208 & 180 & 162 \\
JUNHO & 14 & 120 & 18 & 16 & 68 & 166 & 138 & 56 & 134 & 132 & 48 \\
JULHO & 4 & 9 & 140 & 10 & 8 & 0 & 14 & 30 & 10 & 6 & 8 \\
AGOSTO & 218 & 66 & 142 & 180 & $*$ & 146 & 143 & 140 & 536 & 190 & 118 \\
SETEMBRO & 92 & 204 & 152 & 72 & 74 & 114 & 96 & 76 & 90 & 42 & 92 \\
OUT UBRO & 108 & 96 & 109 & 86 & 106 & 296 & 14 & 52 & 92 & 116 & 300 \\
NOVEMBRO & 24 & 96 & 26 & 64 & 4 & 66 & 26 & 36 & 28 & 36 & 36 \\
DEZEMBRO & 76 & 91 & 94 & 66 & 110 & 143 & 106 & 86 & 73 & 101 & 145 \\
\hline
\end{tabular}

*No mês de agosto não foi feita a coleta de dados no ponto 5 por motivo de reforma. 
Segundo Ferreira (2013), a temperatura tem influência direta na variação do número e do tipo de fungos do ar exterior e interior. Porém, fatores como condições de higiene dos espaços, ocupação, ventilação e umidade também influenciam em sua concentração. A proliferação de fungos em ambientes interiores, além de constituir um perigo para a saúde dos ocupantes, também indica que as condições de umidade relativa podem proporcionar a proliferação de outros agentes biológicos.

Um modo de avaliar o conceito de normalidade, representado pelo meio ambiente exterior e a tendência epidemiológica que os poluentes têm em se amplificar nos ambientes fechados, é por meio do cálculo da relação $\mathrm{I} / \mathrm{E}$, considerando como I como a quantidade de fungos no ambiente interior e E como a quantidade de fungos no ambiente exterior.

Para calcular a relação I/E, o ponto 7 (ambiente externo), foi utilizado como o índice $\mathrm{E}$. $\mathrm{O}$ ponto 5 não entrou nos cálculos, uma vez que o refeitório encontra-se em um ambiente exterior. Os resultados estão apresentados na Tabela 3.

Tabela 3 Relação I/E dos pontos amostrados.

\begin{tabular}{l|l|l|l|l|l|l|l|l|l}
\hline Mês & P1 & P2 & P3 & P4 & P6 & P8 & P9 & P10 & P11 \\
\hline Abril & 0,14 & 0,08 & 0,16 & 0,09 & 0,23 & 0,17 & 0,57 & 0,21 & 0,78 \\
Maio & 0,02 & 0,18 & 0,15 & 0,10 & 0,47 & 0,74 & 0,41 & 0,36 & 0,32 \\
Junho & 0,10 & 0,87 & 0,13 & 0,12 & 1,20 & 0,41 & 0,97 & 0,96 & 0,35 \\
Julho & 0,29 & 0,64 & 10,00 & 0,71 & 0,00 & 2,14 & 0,71 & 0,43 & 0,57 \\
Agosto & 1,52 & 0,46 & 0,99 & 1,26 & 1,02 & 0,98 & 3,75 & 1,33 & 0,83 \\
Setembro & 0,96 & 2,13 & 1,58 & 0,75 & 1,19 & 0,79 & 0,94 & 0,44 & 0,96 \\
Outubro & 7,71 & 6,86 & 7,79 & 6,14 & 21,14 & 3,71 & 6,57 & 8,29 & 21,43 \\
Novembro & 0,92 & 3,69 & 1,00 & 2,46 & 2,54 & 1,38 & 1,08 & 1,38 & 1,38 \\
Dezembro & 0,72 & 0,86 & 0,89 & 0,62 & 1,35 & 0,81 & 0,69 & 0,95 & 1,37 \\
\hline
\end{tabular}

A maior relação é observada no mês de outubro, nos pontos P6 e P11, com valores de 21,14 e 21,43, respectivamente, onde se faz necessário um diagnóstico de fontes para intervenção corretiva.

Embora não tenha sido identificado fungos nesse estudo, vale ressaltar, que é inaceitável a presença de fungos patogênicos e toxigênicos. Ao se identificar quais os micro-organismos estão presentes no ar, pode-se ter uma noção da origem do problema.

De fato, quando os filtros e dutos de ar refrigerado, e até mesmo os ventiladores, não têm uma limpeza da maneira correta, cria-se um ambiente propício para o desenvolvimento de partículas microbianas, sejam elas fungos, vírus, ácaros ou bactérias. Estes microorganismos podem levar os ocupantes dos ambientes a contraírem doenças respiratórias, infecciosas ou alérgicas, tais como Aspergilose, Histoplasmose, Pneumocistose, dentre outras (Cartaxo et al., 2007; Quadros e Lisboa, 2010). Para reduzir o potencial de contaminação biológica, é necessária a adoção de práticas de manutenção dos equipamentos e de limpeza dos sistemas de circulação do ar, que devem ser realizadas mensalmente (CARTAXO et al., 2007).

Morais et al. (2010), avaliaram a qualidade microbiológica do ar interno de uma instituição de ensino superior da cidade de Itumbiara (GO) e concluíram que o ar de $51 \%$ das salas avaliadas estava contaminado com contagens bacterianas acima do limite proposto pela ANVISA, representando um desconforto ao bem estar dos alunos e professores que se expõem por tempo prolongado nestes espaços, podendo ocasionar sérios riscos à saúde. 


\section{CONCLUSÃO}

Ficou evidenciada a relação existente entre temperatura, umidade e contaminação microbiológica. No mês de junho, os pontos que apresentaram contaminação bacteriológica, exibiram altas taxas de temperatura e baixos valores de umidade. Assim como os meses de maio e agosto, que apresentaram alta incidência de fungos, também evidenciaram elevadas taxas de umidade e baixas temperaturas.

A contaminação biológica, aliada à temperatura e umidade dos ambientes escolares, além de causarem desconforto físico e psicológico, desempenham um papel importante na causalidade dos agravos à saúde. A falta de uma política preventiva nos programas de manutenção nos sistemas de refrigeração e ventilação pode ser fator determinante para a ocorrência de poluentes biológicos, que constituem uma ameaça à saúde dos ocupantes da escola.

\section{REFERÊNCIAS BIBLIOGRÁFICAS}

ANVISA - Agência Nacional de Vigilância Sanitária Portaria $n^{\circ} 3523$ de 28 de agosto de 1998. Disponível em: http://bvsms.saude.gov.br/bvs/saudelegis/g m/1998/prt3523_28_08_1998.html.

ANVISA - Agência Nacional de Vigilância Sanitária. Resolução n ${ }^{\circ}$ 9, de 16 de janeiro de 2003. Disponível em: http://portal.anvisa.gov.br/wps/wcm/conne ct/d094d3004e5f8dee981ddcd762e8a5ec/R esolucao_RE_n_09.pdf?MOD=AJPERES. Acesso em: 07 de setembro de 2013.

BATISTA, C A T. Poluição do ar de interiores: uma avaliação de casos relacionados à climatização artificial. Trabalho de conclusão de curso apresentado a Especialização em Análise Ambiental- UFJF - Juiz de Fora/MG. 2008. 48pg.
Cartaxo E F, Gonçalves A C L C, Costa F R, Coelho I M V, Santos J G (2007). Aspectos de contaminação biológica em filtros de condicionadores de ar instalados em domicílios da cidade de Manaus - AM. Revista Engenharia Sanitária e Ambiental, Rio de Janeiro, 12 (2): 202-211. doi.org/10.1590/S1413-

41522007000200011

COMIN, T T. - Monitoramento ambiental em uma escola da cidade de São Carlos SP: ênfase em qualidade do ar interior. (Dissertação apresentada à Pós Graduação em Engenharia Química) - Centro de Ciências e Tecnologias - UFSC - São Carlos/SP. 2012. 166pg.

Davis R E, McGregor G R, Enfield K B (2016) Humidity: A review and primer on atmospheric moisture and human health. Environmental Research, 144 (Pt A): 106116. doi: 10.1016 / j.envres.2015.10.014

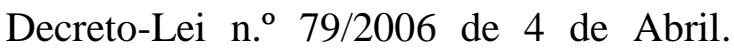
Portugal. Disponível em: http://www.oasrn.org/pdf_upload/decretole i_79_2006.pdf

Ferreira A M C, Cardoso S M (2013) Estudo exploratório da qualidade do ar em escolas de educação básica, Coimbra, Portugal. Revista Saúde Pública, 47 (6): 1059-1068. doi: org/10.1590/S00348910.2013047004810

Madureira J, Paciência I, Rufo J, Ramos E, Barros H, Teixeira J P, Fernandes E $\mathrm{O}(2015)$ Indoor air quality in schools and its relationship with children's respiratory symptoms. Atmospheric Environment, 118: 145-156. doi:10.1016/j.atmosenv.2015.07.028.

Morais G R, Silva M A, Carvalho M V, Santos, J G S, Von Dolinger E J O, Brito D vD (2010) Qualidade do ar interno em uma instituição de ensino superior brasileira. Bioscience Journal, Uberlândia, 26 (2): 305-310. 
NASCIMENTO, G C. - Avaliação da qualidade do ar em ambientes internos: biblioteca pública. Dissertação apresentada a Pós Graduação em Hidráulica e Saneamento - Escola de Engenharia Hidráulica e Saneamento - USP - São Carlos/SP. 2011. 170pg.

ORGANIZAÇÃO MUNDIAL DA SAÚDE (OMS). Air quality guidelines: Environmental health information, 1999.

Disponível em: http://www.who.int/environmental_inform ation_airguidelines/AQGUIDEPREF.HTM

PEREIRA, D. A. M., COUTINHO, A. S., SILVA, L. B. Análise das condições de conforto térmico e da inércia térmica a que professores das escolas municipais de João Pessoa - PB estão submetidos. In: ENCONTRO NACIONAL DE ENGENHARIA DE PRODUÇÃO, 24, 2009, Salvador. Anais... Salvador: ABREPO, 2009.

PEREIRA, D. A. M., LEITE, J. P., BARBOSA, R. F., LIMA, O. F. Avaliação do desempenho da ventilação natural para a promoção do conforto térmico em um bloco educacional público. In: VIII CONGRESSO NACIONAL DE EXCELÊNCIA EM GESTÃO, 8, 2012, Rio de Janeiro, Anais... Rio de Janeiro, 2012.

QUADROS, M. E.; LISBOA, H. M. Controle da poluição atmosférica: qualidade do ar interno. Universidade do Estado do Pará. Pará, 2010.

SILVA, M A A C. - A temperatura e a humidade relativa do ar num contexto educacional. Dissertação de Mestrado apresentada a Pós Graduação em Ensino de Física - Universidade de Aveiro Aveiro/Portugal. 2008. 139pg. 